\title{
Problemas identificados em gráficos estatísticos publicados nos meios de comunicação
}

Problems identified in statistical graphs published in the media

\author{
Rodrigo Medeiros dos Santos ${ }^{1}$ \\ Messias Viana Branches ${ }^{2}$
}

\section{Resumo}

O objetivo desta pesquisa é abordar e analisar alguns exemplos de erros contidos em gráficos estatísticos publicados nos meios de comunicação, buscando a construção de subsídios para a interpretação e análise crítica dessas ferramentas no contexto das práticas de letramento estatístico. A pesquisa tem como principal aporte teórico as ideias sobre letramento estatístico de Iddo Gal. Metodologicamente, a pesquisa é caracterizada como descritiva e bibliográfica. Os principais resultados apontam diversas impropriedades na construção dos gráficos, tais como a ausência do eixo das ordenas, barras dos gráficos com larguras e comprimentos desproporcionais, incompatibilidade dos rótulos dos dados com as medidas apresentadas nos gráficos, entre outros. Os resultados nos levam a ressaltar a necessidade de uma sociedade estatisticamente letrada, bem como nos chama a atenção para a necessidade de uma formação estatística mais adequada para os profissionais da imprensa.

Palavras-chave: Gráficos; meios de comunicação; Letramento Estatístico.

\section{Abstract}

The objective of this research is to approach and analyze some examples of errors in statistical graphs published in the media, seeking the construction of subsidies for the interpretation and critical analysis of these tools in the context of statistical literacy practices. The research has as main theoretical contribution the ideas on statistical literacy of Iddo Gal. Methodologically, the research is characterized as descriptive and bibliographical. The main results point to several improprieties in the construction of the graphs, such as the absence of the $y$-axis, bars of the charts with disproportional widths and lengths, incompatibility of the data labels with the measures presented in the graphs, among others. The results lead us to stress the need for a statistically literate society, as well as draws attention to the need for a more adequate statistical education for media professionals.

Keywords: Graphs; Media; Statistical Literacy.

\footnotetext{
${ }^{1}$ Universidade Federal do Oeste do Pará | rodrigomedeiros182@hotmail.com

${ }^{2}$ Universidade Federal do Oeste do Pará | mvbranx@gmail.com
} 


\section{Introdução}

Sendo a ciência responsável pela coleta, organização, processamento, apresentação e interpretação de dados, a Estatística, com seus métodos, exerce um papel fundamental na comunicação cotidiana, com grande impacto na relação de consumo de informações veiculadas pela imprensa.

Para Souza (2009),

os veículos de comunicação de massa têm nos dados quantitativos uma forma comum de noticiar os fatos. Quer se trate da imprensa escrita ou até da publicidade, todos acabam utilizando dados estatísticos para conferir maior credibilidade à mensagem transmitida (SOUZA, 2009, p. 2).

É possível supor que os dados quantitativos estão presentes em grande escala na mídia, porque, ao serem divulgados, acabam influenciando de alguma maneira a opinião do receptor. O poder midiático dos números reside justamente no fato de que são capazes de descrever fenômenos naturais e humanos de larga escala, possibilitando diagnósticos e conclusões nos mais diversos campos de atuação humana.

O interesse pelo uso dos instrumentos estatísticos pela mídia se justifica porque

os números passam ideia de cientificidade, de isenção, de neutralidade. Quando discursos, propagandas, manchetes e notícias veiculadas pela mídia, utilizam informações Estatísticas (números, tabelas, gráficos), essas ganham credibilidade e são difíceis de serem contestadas pelo cidadão comum (CAZORLA; CASTRO, 2008, p. 2).

Nessa perspectiva, destacamos, no contexto deste artigo, o uso dos gráficos estatísticos em dois extremos, opostos, porém diretamente relacionados. De um lado, o leitor, que consome, analisa e interpreta a informação gráfica publicada; e, do outro, o produtor das informações, na figura do técnico estatístico, do profissional da imprensa, ou, em termos mais gerais, do comunicador responsável pela produção e veiculação das informações publicadas. Em ambos os extremos dessa relação, é imperativo o balizamento, em primeiro lugar, do conhecimento estatístico, no sentido de dar aos elementos gráficos a significação técnica correta e apropriada; e, em segundo lugar, da ética profissional estatística e jornalística, no sentido da imparcialidade e veracidade dos dados.

Huff (2016) nos chama a atenção para um ponto crucial nessa análise: nem todos os erros cometidos em gráficos publicados pela imprensa são produto de manipulação intencional. Alguns casos são produto daquilo que o autor descreve meramente como incompetência. No entanto, ele é taxativo: "[...] não estou certo de que esta presunção seja menos ofensiva, para os estatísticos, que a outra" (HUFF, 2016, p. 93). Em todo caso, é bastante difícil, na maioria das vezes, fazer esse julgamento (manipulação intencional ou incompetência). E esse tampouco é o objetivo desta pesquisa. 
Daí que nosso foco esteja essencialmente em discutir alguns exemplos de erros contidos em gráficos estatísticos publicados em websites, livros, revistas e portais de notícias, buscando a análise dessas ferramentas no contexto das práticas de letramento estatístico. Os exemplos são apresentados e seus principais aspectos técnicos são explorados e discutidos.

\section{Letramento estatístico}

Ferramentas estatísticas, tais como gráficos, têm o potencial de agrupar sinteticamente um grande número de dados. Em grande medida, o apelo para seu uso deve-se à eficiência para transmitir visualmente informações de forma mais resumida, amena e prazerosa. E, se por um lado, são ferramentas que facilitam e viabilizam o consumo de uma imensa quantidade de dados de forma prática e (relativamente) simples; por outro lado, exigem, tanto por parte do emissor quanto do receptor da informação, um certo grau de conhecimento técnico - digamos, para sermos mais específicos, um certo grau de letramento.

O letramento estatístico, segundo Gal (2002), é definido como a habilidade de interpretar, avaliar criticamente e comunicar mensagens e informações estatísticas. Pode ser descrito, ainda segundo o autor, a partir de dois componentes inter-relacionados: (a) a habilidade das pessoas de interpretar e avaliar criticamente informações estatísticas, argumentos relacionados a dados, ou fenômenos estocásticos; (b) a habilidade de discutir ou comunicar suas reações à informação estatística, assim como o seu entendimento do significado da informação, as opiniões a respeito de suas implicações, ou as suas preocupações em relação à aceitabilidade das conclusões obtidas.

Gal (2002) propõe um modelo, resumido no Quadro 1, que assume que o letramento estatístico envolve tanto um componente de conhecimento (representado por cinco elementos cognitivos: habilidades de letramento, conhecimento estatístico, conhecimento matemático, conhecimento do contexto e questões críticas) quanto um componente disposicional (representado por dois elementos: postura crítica e crenças e atitudes).

Quadro 1 - O modelo de letramento estatístico de Gal (2002).

\begin{tabular}{|l|l|}
\hline Elementos de Conhecimento & Elementos de disposição \\
\hline Habilidades de letramento & Crenças e atitudes \\
Conhecimento estatístico & Postura crítica \\
Conhecimento matemático & \\
Conhecimento do contexto & \\
Questões críticas
\end{tabular}

Fonte: Gal (2002) 
A observação deste modelo embasa as discussões aqui engendradas na medida em que alguns exemplos de gráficos são analisados na esteira das ideias trazidas pelo modelo proposto. O confronto dos exemplos apresentados com essas ideias visa fazer emergir alguns aspectos de importância na discussão da qualidade e veracidade das informações gráficas acessadas nos meios de comunicação.

\section{Apontamentos metodológicos}

A presente pesquisa caracteriza-se, segundo seus objetivos, como descritiva, que, na indicação de Fiorentini e Lorenzato (2010), visa descrever ou caracterizar com detalhe uma situação, um fenômeno ou um problema. Já em relação aos processos de coleta dos dados, a pesquisa é descrita como de natureza bibliográfica, que, para os mesmos autores supracitados, "é aquela que se faz preferencialmente sobre documentação escrita" (FIORENTINI; LORENZATO, 2010, p.102). O aporte teórico da pesquisa está nas ideias sobre letramento estatístico constantes em Gal (2002).

Buscamos, portanto, com o presente trabalho, fazer uma análise de alguns gráficos estatísticos publicados em meios de comunicação, discutindo os diferentes aspectos de sua estrutura, com o objetivo de criar subsídios que possam servir de parâmetros a serem utilizados para melhor compreensão dos mesmos.

O material de análise foi coletado predominantemente em revistas impressas, livros, websites e portais de notícias online. Após um processo de triagem, alguns exemplos de gráficos foram selecionados de acordo com as suas potencialidades para a exploração de aspectos estruturais e conceituais. Esses aspectos são aqui discutidos na esteira do contexto em que os gráficos foram publicados. A pesquisa está ancorada no fato de que os erros cometidos nesses gráficos representam território fértil de exploração conceitual.

\section{Análise e discussão}

A seguir, são apresentados e discutidos alguns exemplos de gráficos estatísticos diversos retirados de meios de comunicação. Alguns problemas identificados nesses gráficos são explorados e analisados. As principais discussões não giram em torno de possíveis casos de falsificação dos dados - o que seria de difícil averiguação na prática -, mas em torno de distorções na apresentação dos dados, manifestadas em problemas conceituais na elaboração dos gráficos.

Iniciemos nossa análise com um exemplo clássico e recorrente em épocas de campanha eleitoral. Resultados de pesquisa eleitoral publicados com intuito de promoção de campanha são, em geral, um espaço propício a distorções gráficas cometidas com o intuito de ressaltar, mais que o devido, uma vitória parcial de determinado candidato.

Em 2016, o portal de notícias El País publicou uma reportagem sobre a lisura das pesquisas eleitorais no Brasil. A reportagem apresentou um gráfico de colunas mostrando o 
resultado de uma pesquisa popular de intenção de votos no segundo turno da campanha eleitoral para a presidência da república no ano de 2014. A pesquisa fora realizada pelo instituto Paraná, e mostrou que o então candidato Aécio Neves aparecia à frente da candidata Dilma Rousseff (Figura 1).

Figura 1 - Pesquisa de intenção de votos para a presidência da república - 2014.

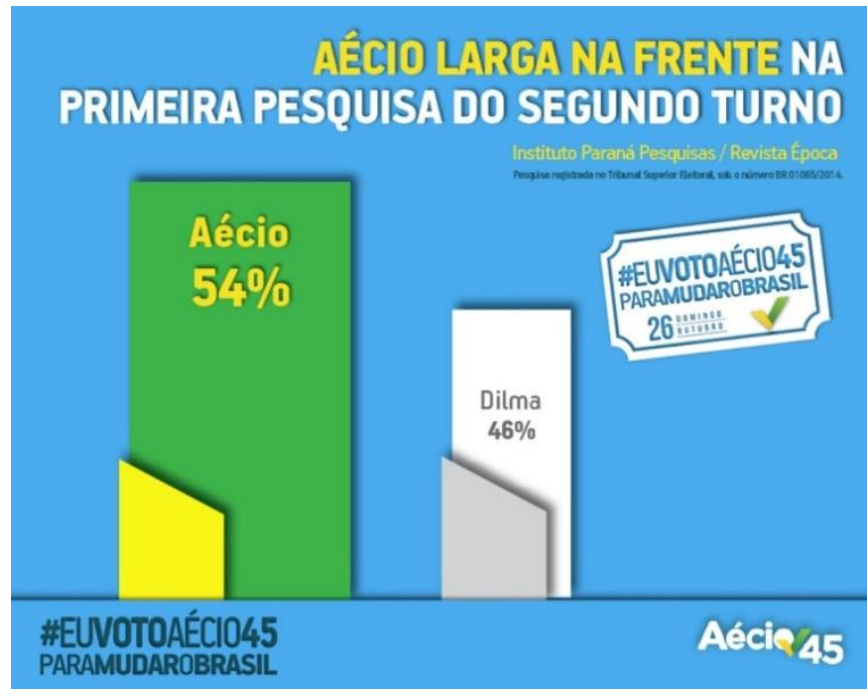

Fonte: El País (http://www.brasil.elpais.com).

A partir da leitura do gráfico da Figura 1, notamos que a coluna que representa o candidato Aécio Neves aparece com largura superior à da coluna que representa a candidata Dilma Rousseff. Esta primeira observação já implica em um desvio normativo na elaboração de gráficos estatísticos, dado que, via de regra, as colunas só devem diferir em comprimento, e não em largura (TOLEDO e OVALLE, 1981). Isso pode ser interpretado como uma forma de tentar destacar ainda mais a vantagem mostrada na pesquisa - assim como as cores vivas utilizadas na coluna do candidato, em contraste com as cores neutras na coluna da adversária.

Esse tipo de recurso, repleto de parcialidade em sua natureza, é comumente utilizado quando o comitê eleitoral de um dos candidatos envolvidos na eleição é o próprio responsável pela construção do gráfico (a reportagem afirma que a Figura foi retirada diretamente de uma rede social do candidato em questão).

Naturalmente que, no campo ético, a publicação de um gráfico advindo de uma fonte destituída de neutralidade acaba contribuindo para a propagação desse tipo de distorção dos fatos, ao mesmo passo que, no campo técnico, a diferença entre as larguras observada na Figura 1 fere um princípio de veracidade no gráfico.

Gal (2002), ao discutir as habilidades críticas de letramento dentro do componente de conhecimento proposto em seu modelo de letramento estatístico, aborda este problema afirmando que

Os criadores de mensagens podem ter diversos objetivos em termos dos fatos presumidos, imagens, ou conclusões que visam criar ou incutir na mente do leitor. Algumas mensagens podem ser criadas para convencer o 
leitor ou ouvinte a adotar um ponto de vista específico ou rejeitar outro, e, portanto, usar argumentos unilaterais ou apresentar informação seletiva (GAL, 2002, p. 7).

O autor ainda alerta para o fato de que "mensagens dirigidas aos cidadãos em geral podem ser moldadas por agendas políticas, comerciais ou outras" (GAL, 2002, p. 15). Mas essa não é a única questão digna de nota na análise do gráfico da Figura 1. Notemos ainda que a ausência de elementos comparativos de referência no gráfico (eixo vertical, escalas, linhas de grade) impossibilitam a criação de parâmetros sistemáticos de comparação entre as duas colunas, "forçando", por assim dizer, o leitor a acreditar na informação visual trazida pelo gráfico. Entretanto, ao compararmos os comprimentos das duas colunas, verificamos que há uma incompatibilidade entre as medidas de seus comprimentos e os valores mostrados nos rótulos dos dados. Na verdade, a coluna representada pela proporção da intenção de votos da então candidata Dilma Roussef é mostrada no gráfico com comprimento aproximadamente $19 \%$ inferior ao comprimento que, de fato, deveria apresentar para estar compatível com os rótulos de dados apresentados.

A principal ideia relacionada à comparação dos comprimentos das colunas neste tipo de gráfico é justamente enfatizar as diferenças entre as frequências (absolutas ou relativas) representadas por cada categoria pesquisada. É possível afirmar que, na forma em que o gráfico em questão foi apresentado, essa diferença parece visualmente maior do que deveria ser. E a ausência dos elementos comparativos de referência, assim como o aumento intencional da largura da coluna do candidato, dificultam ainda mais a leitura, distorcendo os dados e apresentando uma discrepância visual, na qual os elementos gráficos são incompatíveis com os rótulos mostrados.

A seguir, discutimos duas práticas muito comuns entre os profissionais da imprensa na elaboração de gráficos estatísticos, a omissão do zero e a interrupção da escala no eixo vertical.

Iniciamos essa discussão abordando um exemplo de gráfico publicado no portal de notícias G1, em junho de 2011. A reportagem intitulada "Na bolsa, crise grega 'apaga' bom momento da economia brasileira", traz como destaque a queda de desempenho nos índices da Ibovespa em função da crise das atividades econômicas europeia e norteamericana. Um gráfico de linhas apresenta o desempenho dos índices da Ibovespa de junho de 2010 a maio de 2011, conforme mostra a Figura 2.

Na Figura 2, é possível observar que o eixo vertical é iniciado no gráfico a partir do valor 60.000. Esse recurso de interrupção da escala no início do eixo vertical, bastante popular na imprensa, é comumente utilizado quando o menor valor observado na série de dados é significativamente maior que zero. Nesses casos, a grande extensão da escala no eixo vertical provoca um espaço inútil entre a linha do gráfico e o eixo horizontal. Busca-se então eliminar este espaço inútil, tanto por uma questão de simplificação e economia de espaço no gráfico, como por meio de dar um maior foco ao intervalo em que os dados encontram-se apresentados. 
Figura 2 - Variação do índice Ibovespa, de junho de 2010 até maio de 2011.

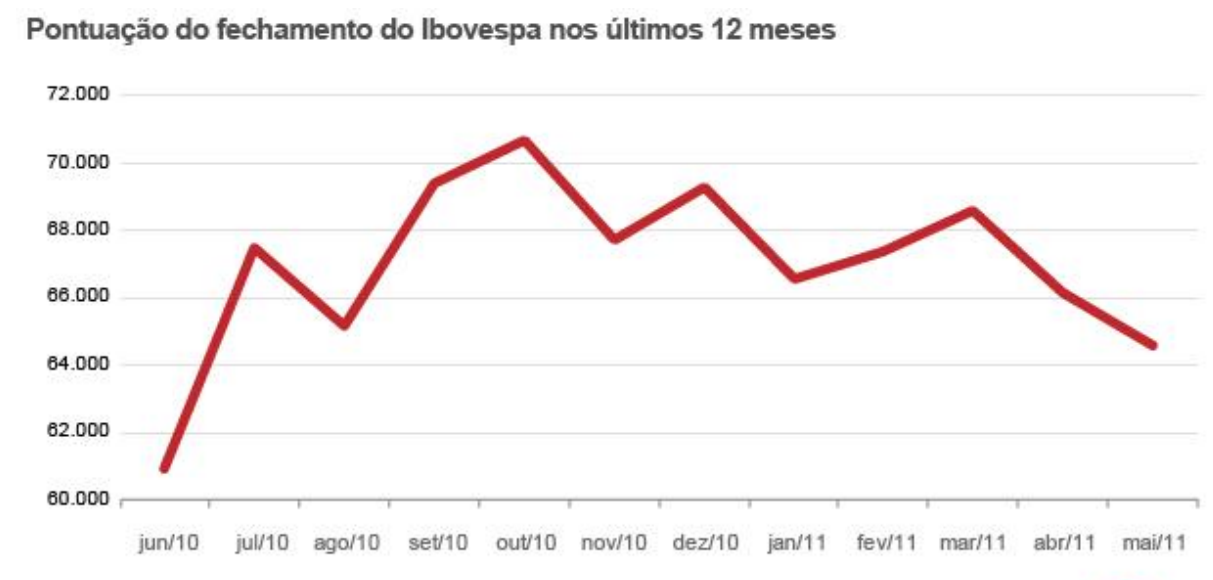

Fonte: Bovespa

G. com.br

Fonte: Portal G1 (http://www.g1.globo.com).

Em nosso levantamento bibliográfico, encontramos diversos exemplos de gráficos de linhas nos quais o eixo vertical não inicia-se no zero. Em alguns desses casos, não é sequer indicado o valor no qual o eixo vertical inicia-se, como mostra o exemplo da Figura 3, encontrado na edição de junho de 2017 da Revista Exame.

Figura 3 - Previsão da produção/importação diária de gás natural no Brasil.

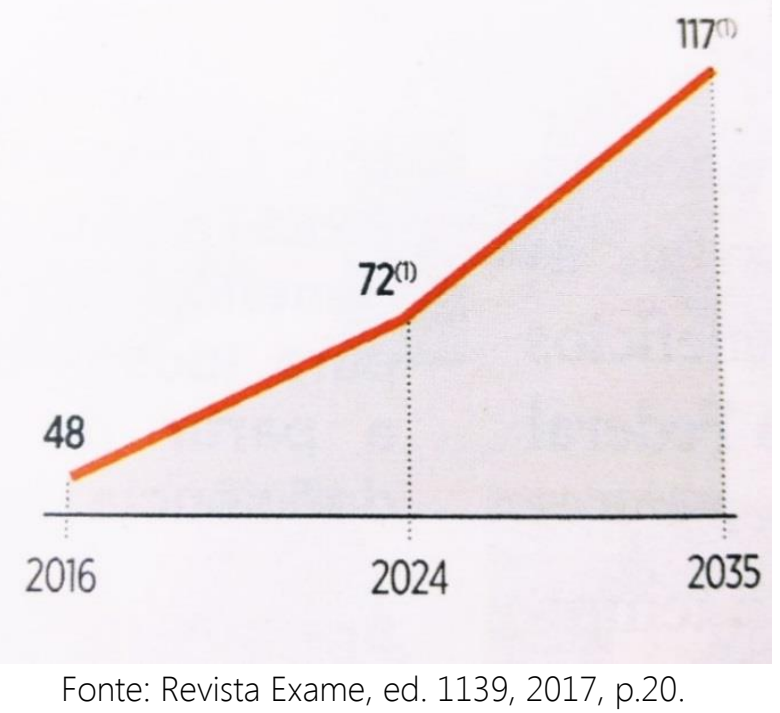

No gráfico exibido na Figura 3, vamos notar que, em relação ao eixo das abscissas, o ponto 72 possui altura pelo menos quatro vezes maior que o ponto 48, o que é absurdo. A omissão do zero e um salto inadvertido na escala são as explicações encontradas para as incongruências observadas no gráfico. Na ausência total da escala e do zero, tomar o menor valor da série de dados como referência pode causar problemas na interpretação, pois, como podemos observar no gráfico da Figura 4, o ponto 48 não está distante a 48 unidades do eixo das abscissas. 
Mas, afinal, é inadequada a omissão do zero no eixo vertical em gráficos de linha? A respeito dessa questão, Crespo (2002) esclarece:

O zero, de modo geral, deverá ser indicado sempre que possível, especialmente no eixo vertical (grifo nosso). Se, por alguma razão, for impossível tal indicação e se essa omissão puder levar o observador a conclusões errôneas, é prudente chamar a atenção para a omissão (CRESPO, 2002, p. 40).

O autor então indica quatro meios de chamar a atenção para a omissão do zero em gráficos de linha, conforme mostrado na Figura 4.

Figura 4 - Quatro exemplos de como indicar a omissão do zero em gráficos de linha.
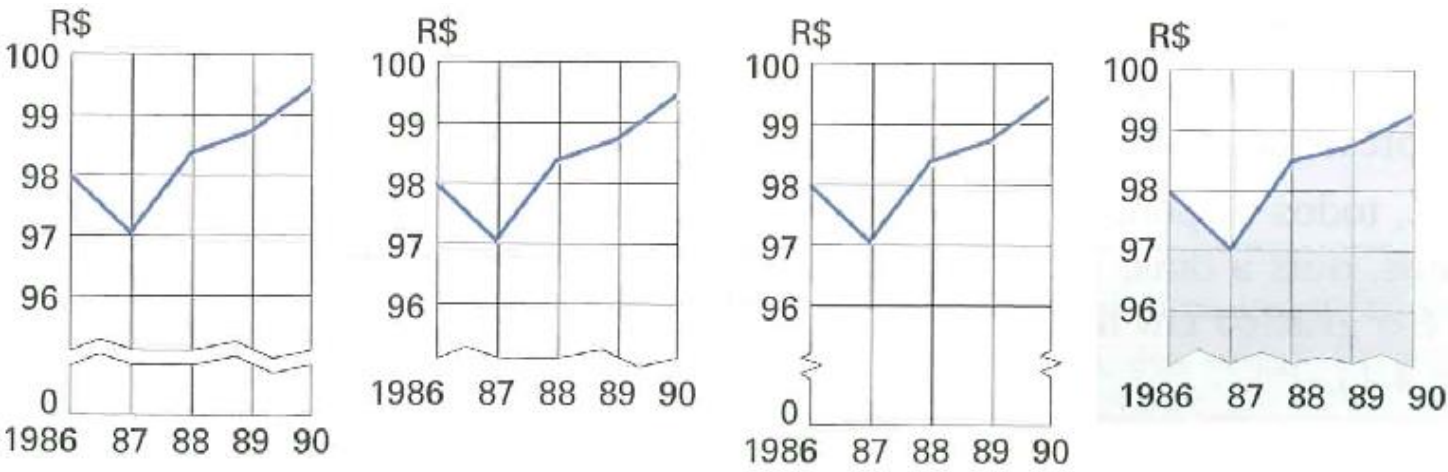

Fonte: Crespo (2002).

Conforme podemos notar na análise da Figura 4, uma das formas de lidar com a questão é mostrar o zero e indicar, a partir de uma "quebra" ou de uma linha em ziguezague, a interrupção da escala. Sobre essa questão, Toledo e Ovalle (1981) alertam:

O uso de uma escala interrompida, entretanto, deve ser feito com cautela, uma vez que ela distorce parcialmente a perspectiva do gráfico. Assim, uma pequena variação na intensidade do fenômeno pode parecer de grandes proporções quando a escala for interrompida, uma vez que a atenção do leitor se concentrará apenas nos pontos da escala realmente significativos (TOLEDO; OVALLE, 1981, p. 87).

Fazer um recorte do gráfico apenas no intervalo em que os dados estão manifestados cria o efeito de "zoom", uma aproximação visual a determinada área do gráfico que, por sua vez, contribui para que sejam ressaltas indevidamente as tendências de variação dos dados. Em suma, "o olho não 'entende' o que não está ali, e uma subida pequena se torna, visualmente, uma subida grande" (HUFF, 2016, p. 73).

Devemos atentar ainda para o fato de que a interrupção da escala ou a omissão do zero, mesmo quando devidamente indicadas, como mostrado na Figura 4, podem não adequar-se devidamente a outros tipos de gráficos. Para abordarmos essa questão, exploraremos um exemplo retirado de um blog jornalístico denominado Blog do Jeso. Nele, 
foi publicada, em 9 de abril de 2017, uma reportagem sobre as ações trabalhistas movidas contra a Aqua Empreendimentos, empresa responsável pela construção de um edifício residencial na cidade de Santarém-PA. As ações foram movidas por trabalhadores que prestaram serviços à empresa na execução da obra.

Na matéria, o jornalista criou um gráfico de colunas para mostrar o número de ações em tramitação contra a empresa na justiça do trabalho nas cidades de Santarém e Óbidos, ambas no estado do Pará, conforme nos mostra a Figura 5.

Figura 5 - Número de Ações movidas contra a empresa Aqua Empreendimentos nas cidades de Santarém e Óbidos, em 2017.

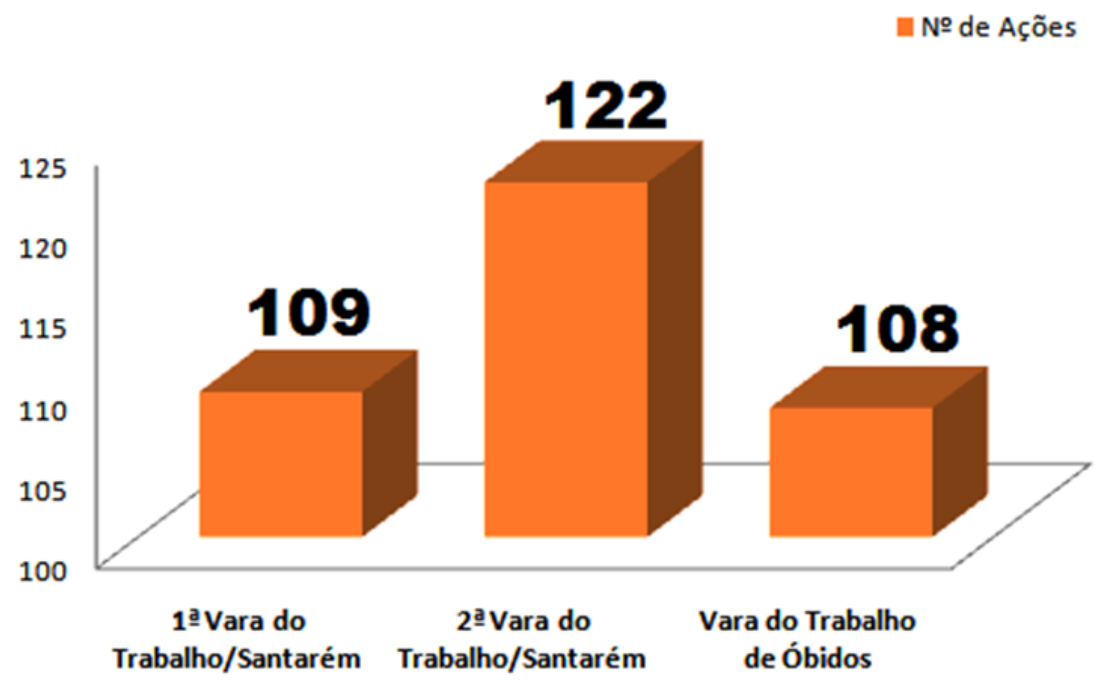

Fonte: Blog do Jeso (http://www.jesocarneiro.com.br)

Nesse exemplo, é possível verificar que o autor do gráfico lançou mão do recurso da interrupção da escala no eixo vertical, iniciando-o no valor 100. Como decorrência dessa decisão, o corte imposto às colunas terminou por afetar drasticamente a proporção dos comprimentos dessas colunas, gerando discrepâncias visuais. Basta notarmos que a coluna de rótulo 122 possui mais que o dobro do comprimento das colunas de rótulos 109 e 108, o que é absurdo. Na verdade, ao invés de compararmos visualmente as colunas de rótulos 109, 122 e 108, o que estamos efetivamente comparando no gráfico são as colunas de rótulos nove, 22 e oito, respectivamente, uma vez que todas elas iniciam-se no valor 100. Ao cortar as colunas na altura do valor 100, o autor impõe uma comparação apenas entre os topos das colunas.

No contexto do modelo de letramento estatístico elaborado por Gal (2002), notamos no gráfico da Figura 5 um problema ligado notadamente ao aspecto do conhecimento matemático, no qual o autor foi incapaz de avaliar as proporções das alturas de cada coluna em relação aos rótulos dos dados.

Como pudemos observar, a interrupção na escala do eixo vertical no contexto dos gráficos de colunas altera a informação ainda mais que no contexto dos gráficos de linhas. $\mathrm{E}$ aqui não há atenuantes, este tipo de procedimento em gráficos de colunas (e, 
consequentemente, também nos de barras) invalida as informações apresentadas, trazendo ao observador uma apresentação completamente equivocada dos dados. Na esteira dessa discussão, Toledo e Ovalle (1981, p. 80) ainda elucidam que "um gráfico [de colunas ou de barras], construído para mostrar grandezas absolutas, deverá ter uma linha zero claramente definida e uma escala de quantidades ininterrupta (grifo nosso), caso contrário a leitura e a interpretação do gráfico poderão ficar distorcidas".

É possível que, na Figura 5, ao iniciar a escala do eixo vertical no valor 100, o autor tenha tido a intenção de eliminar o que julgou ser espaço inútil, buscando reduzir o tamanho do gráfico e "adequá-lo" ao espaço destinado à sua publicação. Uma possível solução para esse problema seria iniciar a escala do eixo vertical no valor zero e aumentar os valores do intervalo da escala de cinco para 20, por exemplo. Esse procedimento, simples em sua natureza, resulta em um gráfico de tamanho adequado e com as proporções corretas entre as colunas, conforme mostramos no gráfico elaborado por nós na Figura 6.

Figura 6 - Número de Ações movidas contra a empresa Aqua Empreendimentos nas cidades de Santarém e Óbidos, em 2017 (refeito).

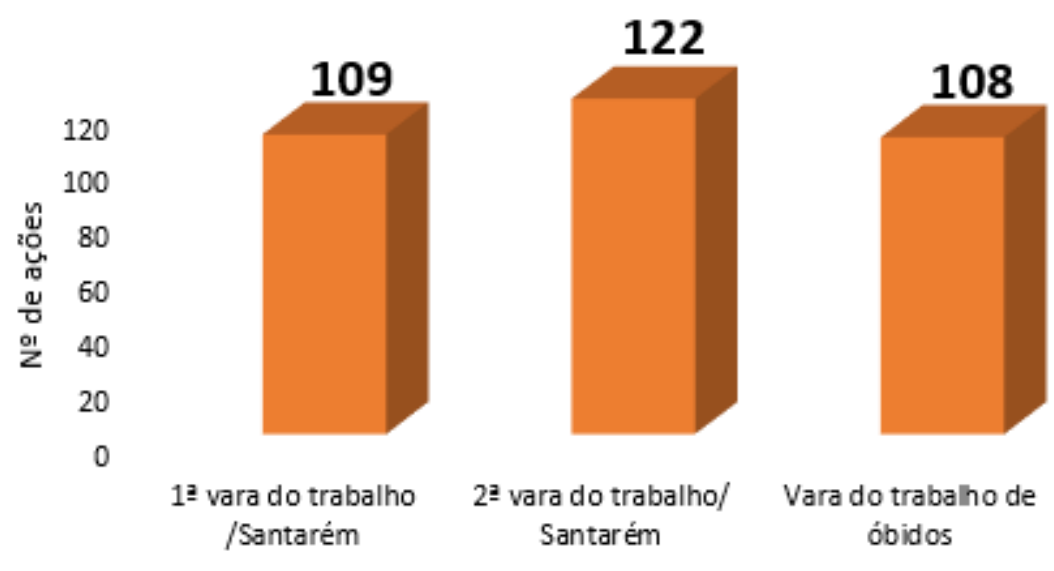

Fonte: Blog do Jeso (http://www.jesocarneiro.com.br)

A despeito do fato de descreverem os mesmos dados, os gráficos das Figuras 5 e 6, em comparação, apresentam informações visuais totalmente distintas. E isso decorre unicamente de mudanças realizadas nas escalas dos gráficos (e não nos dados). Daí que seja imperativo dar toda importância à utilização correta e adequada das escalas em gráficos estatísticos, fator constantemente negligenciado na utilização dessas ferramentas.

Para demonstrarmos a importância dos cuidados a serem tomados na utilização da escala, vamos ilustrar nossa análise com um novo exemplo publicado no portal R7 (Figura 7). 
Figura 7 - Rendimento médio mensal do trabalhador no Brasil, de 1995 a 2015.

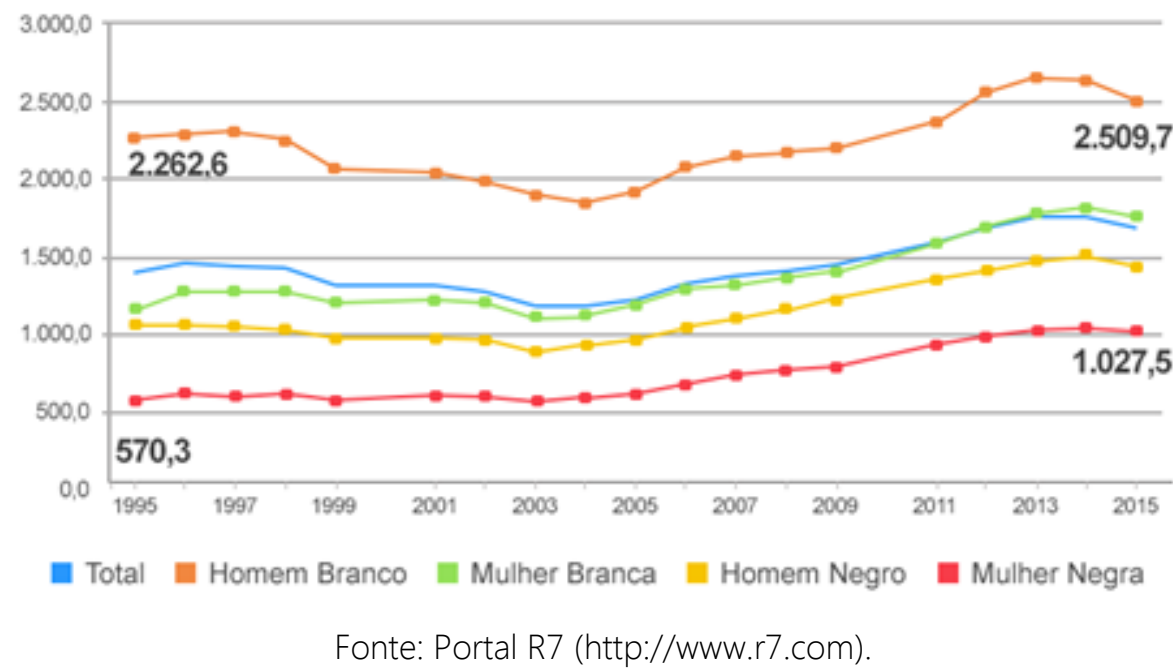

A Figura 7 traz um gráfico de linhas que mostra o comportamento da variável rendimento médio mensal para grupos de pessoas de diferentes sexos e cores de pele, no período que vai de 1995 a 2015, no Brasil. Nele, podemos observar a decisão do autor em utilizar uma escala de largura 500. É notório que escalas demasiadamente largas tendem a atenuar as mudanças nas flutuações, levando o observador a subestimar mudanças nas tendências e fazendo parecer que as curvas são menos acentuadas do que, de fato, são. De maneira análoga, podemos afirmar que escalas demasiadamente curtas tendem a acentuar e superestimar as mudanças nas flutuações observadas no gráfico. Este é um estratagema muito eficiente quando existe o desejo de alterar a apresentação sem alterar os dados, pois, "em geral, o leitor é sensível à forma da curva e não vai olhar as unidades" (BESSON, 1992, p. 205).

Em seu livro intitulado A ilusão das estatísticas, Besson (1992) apresenta um exemplo extremo de como a manipulação das escalas afeta profundamente a impressão passada pelo gráfico (Figura 8).

Figura 8 - Exemplo do mesmo gráfico apresentado com escalas distintas.

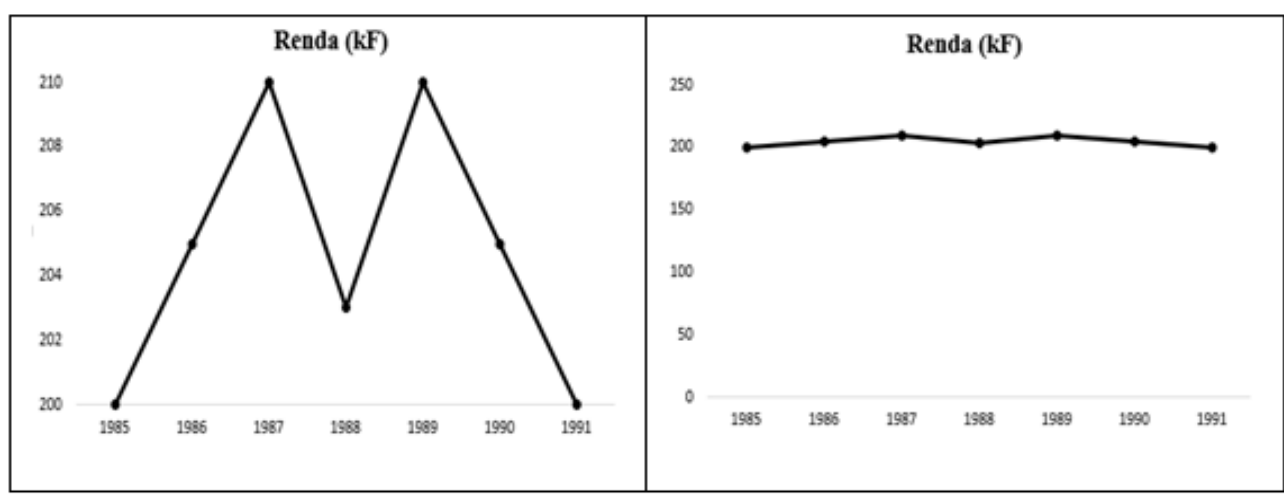

Fonte: Besson (1992) 
Na figura 8, podemos notar como, ainda que tomando o mesmo conjunto de dados, a disposição da escala altera completamente a ideia de flutuação dos dados, saindo de um contexto de aparente instabilidade para outro de aparente estabilidade (sem que os dados sejam alterados de um gráfico para outro, apenas a escala foi mudada). Podemos, diante dessa constatação, avaliar como as flutuações presentes no gráfico da Figura 7 foram suavizadas pela utilização de uma escala tão larga (500). Esse tipo de manipulação da escala afeta de forma substancial a interpretação do fenômeno estudado, na medida em que é capaz de atenuar ou agravar, dependendo do caso, as tendências de variação dos dados.

O exemplo a seguir, mostrado na Figura 9, foi publicado em 21 de março de 2017, no portal de notícias $\mathrm{G} 1$, em uma matéria que abordava temas relacionados ao racismo e à discriminação. A matéria em questão fazia referência a alguns números retirados do questionário do senso Escolar 2015, aplicado pelo Instituto Nacional de Estudos e Pesquisas Educacionais Anísio Teixeira (Inep), do qual participaram 52 mil diretores de escolas públicas de todo o País.

Figura 9 - Respostas de 52 mil diretores de Escolas públicas de todo o país no questionário do censo escolar de 2015.

Na sua escola, há projetos na temática de racismo?

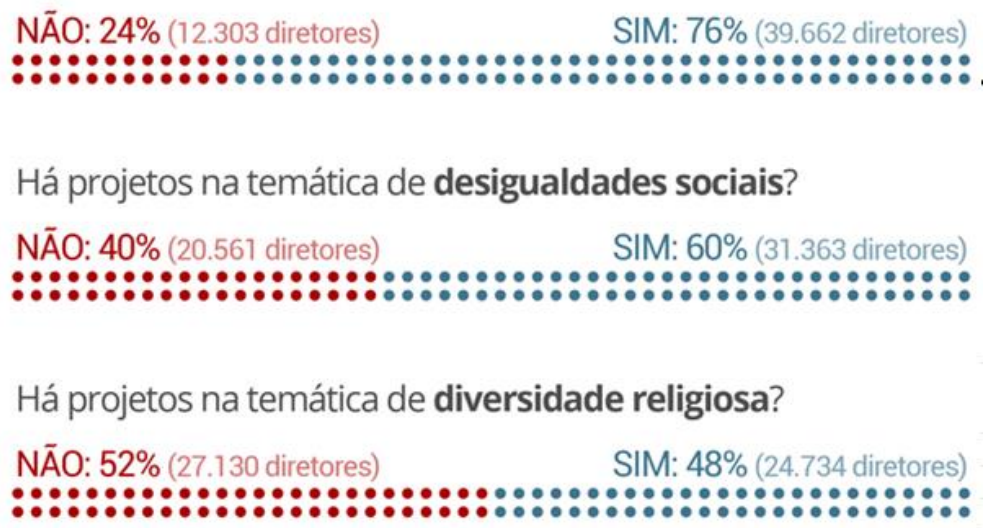

Fonte: Portal G1 (http://www.g1.globo.com).

No pictograma apresentado na Figura 9 observamos as proporções das respostas dicotômicas (sim ou não) para três perguntas. Nas três é possível notar que a proporção de bolas vermelhas (resposta não) é perfeitamente compatível com os rótulos dos dados. Já para as bolas azuis (resposta sim) a proporção é incompatível com os rótulos apresentados. Isso ocorre nas três perguntas. Em todas elas a proporção de respostas sim (bolas azuis) é visualmente maior do que indicam os dados. No caso da última pergunta ("Há projetos na temática de diversidade religiosa?"), é possível notar que a proporção de bolas azuis e vermelhas no gráfico é a mesma, ainda que as respostas sejam 52\% (não) e 48\% (sim).

Huff (2016) tem chamado a atenção para o uso indiscriminado de pictogramas, também conhecidos como gráficos pictóricos, descrevendo-os como "um recurso útil. Têm o que, receio eu, chama-se apelo visual (grifo do autor). E é capaz de tornar-se um 
mentiroso fluente, escorregadio e bem-sucedido" (HUFF, 2016, p. 63). O autor apresenta um exemplo emblemático, mostrado na Figura 10, de como os pictogramas podem ser utilizados para formar uma ideia equivocada a respeito de um determinado fenômeno.

Figura 10 - Comparação entre os salários semanais médios dos carpinteiros nos Estados Unidos e na Rotúndia.
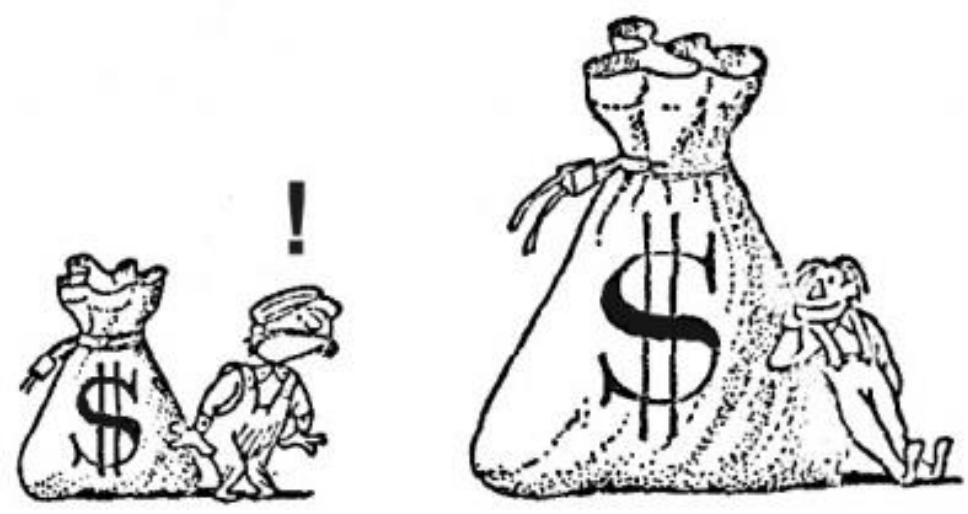

Fonte: Huff (2016)

De acordo com o exemplo abordado, os salários médios semanais dos carpinteiros dos Estados Unidos e da Rotúndia são, respectivamente, 60 e 30 dólares. Esses salários são representados na Figura 10 pelos sacos de dinheiro. Ao observarmos o gráfico, percebemos que, de fato, o comprimento do saco maior equivale ao dobro do comprimento do saco menor. No entanto, ele possui também o dobro da largura, o que, por sua vez, resulta não no dobro da área, mas sim no quádruplo (representação bidimensional). E, ainda que os números digam "dois pra um", a impressão visual passada - geralmente aquela que predomina - diz que essa proporção é, na verdade, "quatro pra um". Besson (1992, p. 253), acrescenta que "o olho e o cérebro humanos são sensíveis às diferenças de superfície e não de altura [...]. Daí um erro completo de leitura, que a observação da escala vertical e das cifras associadas não é suficiente para dissipá-lo totalmente".

Gal (2002), no contexto do conhecimento estatístico inserido no componente de conhecimento proposto em seu modelo, ainda nos alerta para o fato de que a própria escolha do gráfico a ser utilizado pode alterar a percepção dos dados, uma vez que diferentes gráficos podem levar a diferentes visões (e possivelmente visões conflitantes) do mesmo fenômeno estudado.

O agravante no caso dos pictogramas é que, por seu apelo lúdico e, por vezes, cômico, esta modalidade de gráfico acaba, muitas das vezes, cedendo a um certo afrouxamento no rigor matemático. Esse afrouxamento é produto das liberdades criativa e artística das quais o autor goza no intento de tornar o gráfico mais "atraente" e menos "técnico" ao público leigo. São criadas, portanto, alegorias visuais típicas a esta modalidade gráfica, nas quais comumente colunas e barras são substituídas por figuras alusivas ao problema que está sendo abordado. Vejamos, por exemplo, o caso do pictograma publicado no portal IG notícias, em fevereiro de 2011, mostrado na Figura 11. 
Figura 11: Número de jovens e número de matriculados no ensino médio brasileiro, de acordo com o censo 2010.



Fonte: Portal IG notícias (http://www.ultimosegundo.ig.com.br).

Notamos no gráfico que cada unidade de milhão é representada pela figura de um boneco. Assim sendo, o último boneco de cada fila representaria o valor 0,4 milhão. Mas notemos como esses dois últimos bonecos de cada fila, embora representem a mesma quantidade, apresentam áreas preenchidas diferentes. E, apesar de essa diferença ser aparentemente pequena, precisamos lembrar que cada figura de boneco representa um milhão de pessoas, o que, por sua vez, significa que o erro cometido está possivelmente na casa dos milhares.

O gráfico mostrado na Figura 11 é um exemplo emblemático de como o apelo artístico sobrepõe a precisão matemática no gráfico. Isso ocorre, em grande medida, porque a qualidade gráfica dos pictogramas comumente publicados na imprensa exige que este trabalho seja feito, em muitos dos casos, por um profissional do campo do design gráfico, mais comprometido com a qualidade gráfica de seu trabalho e menos com a precisão estatística dos dados. Este fator leva-nos a considerar a problemática da formação estatística dos profissionais ligados à imprensa.

Também é verdade que muitos portais de notícias não possuem o auxílio de consultoria de um profissional da Estatística na elaboração e revisão dos gráficos produzidos. Porém, ainda que um profissional da Estatística esteja por trás da produção dos dados, em última instância esses dados são transformados em notícia pelo profissional da imprensa. É essa ordem dos fatos que dá ao jornalista a palavra final, o que, por sua vez, pode contribuir para distorções do dado estatístico. De fato,

[...] o mais importante é lembrar que a distorção do dado estatístico e sua manipulação para determinado fim não são sempre obra de profissionais da Estatística. O que vem cheio de virtude, lá da mesa dos estatísticos, pode ser torcido, exagerado, simplificado e distorcido [ver novamente o exemplo da Figura 1 deste artigo] - por seleção - pelos [...] jornalistas ou propagandistas (HUFF, 2016, p. 93). 
Gráficos estatísticos, por seu apelo visual, são ferramentas mais passíveis de manipulação que as tabelas estatísticas, por exemplo, nas quais a soma dos valores absolutos deve ser igual ao tamanho da amostra (ou da população), e a soma dos valores relativos deve ser igual a 100\%. Em suma, a conta precisa "fechar". Gráficos são ferramentas menos analíticas que as tabelas, sua função é passar uma impressão visual mais geral, rápida e agradável do fenômeno estudado, daí que sejam mais passíveis de sofrer exageros e distorções que contradizem os próprios dados a partir dos quais foram produzidos.

\section{Considerações finais}

Neste artigo, buscamos analisar alguns exemplos de erros cometidos em gráficos estatísticos publicados nos meios de comunicação, explorando e discutindo os principais aspectos conceituais em cada caso. Enumeramos a seguir, em caráter de síntese, alguns dos principais problemas observados nos gráficos analisados:

- Larguras diferentes das colunas que representam as categorias em gráficos de colunas;

- Comprimentos das colunas incompatíveis com os rótulos apresentados;

- Omissão do zero e interrupção da escala no início do eixo vertical em gráficos de linhas de forma inadvertida;

- Interrupção da escala no início do eixo vertical em gráficos de colunas;

- Ausência total de elementos comparativos de referência nos gráficos (eixo vertical, escalas, linhas de grade);

- Uso de escalas muito largas ou muito estreitas;

- Imprecisão das figuras alegóricas dentro de pictogramas.

Um fator de grande relevância na avaliação dos casos de erros (intencionais ou não) cometidos nos gráficos analisados, é a ausência total do eixo vertical. É crucial entendermos que, para confundir, é necessário omitir do leitor os elementos de referência. O eixo vertical, acompanhado de uma escala adequada e bem definida, quando presentes, são elementos difíceis de burlar, já que dão, matematicamente, as medidas dos pontos ou das colunas plotadas nos gráficos, tornando qualquer erro grosseiro. A premissa omitir para confundir abre espaço para toda sorte de confusões e interpretações equivocadas. Portanto, em uma primeira análise, a ausência desses elementos de referência deve ser o primeiro fator observado pelo leitor ao interpretar um gráfico estatístico.

Ao leitor cabe também uma postura inquisidora e exercício do senso crítico na análise de qualquer informação estatística, o que nem sempre é uma tarefa fácil, pois essa análise demanda a mobilização de habilidades e características específicas (elementos de conhecimento e elementos disposicionais). Essa premissa pode ser estendida ainda a outros ramos da atividade humana que não propriamente a análise gráfica, uma vez que a compreensão dos conceitos de chance e aleatoriedade, por exemplo, está diretamente ligada à nossa vivência cotidiana. Afinal, por que tantas pessoas jogam na loteria, ao passo 
que tantas outras têm medo de voar? O nosso comportamento é moldado, dentre outras coisas, pela nossa compreensão das estatísticas e dos riscos. Em outras palavras, está ligada ao nosso grau de letramento estatístico.

Outro fator potencialmente complicador é a publicação de dados estatísticos destituídos de informações complementares essenciais para a interpretação do fenômeno estudado, tais como o processo de amostragem, o tamanho da amostra, o nível de confiança adotado ou a margem de erro da pesquisa. A ausência dessas informações pode demandar um peso ainda maior nas habilidades de letramento do leitor, que deve tirar suas conclusões sem conhecer aspectos fundamentais a respeito do delineamento metodológico da pesquisa.

A necessidade de uma formação estatística mais adequada nas escolas e universidades é um problema que tem sido debatido com frequência na literatura da área ${ }^{3}$. A questão da elaboração/interpretação de gráficos estatísticos é apenas uma manifestação desse problema de escala maior. Nosso sistema escolar não tem dado a essa questão a devida importância, e isso inclui a abordagem dada nos livros didáticos, nos quais a ênfase está mais no cálculo e obtenção de medidas, e menos na interpretação analítica das ferramentas estatísticas.

Outra questão de interesse está ligada à forma como as pessoas consomem as informações estatísticas nos meios de comunicação. É da própria natureza das ferramentas gráficas fornecer uma impressão visual rápida do fenômeno estudado. Daí que o leitor já esteja predisposto a dar uma "olhada rápida", captando as suas principais impressões, o que, por sua vez, não favorece uma interpretação crítica, muito menos uma possível identificação de erros porventura cometidos. Basta verificarmos que, nos jornais televisivos, por exemplo, o tempo de exibição dos gráficos é de apenas alguns segundos. Compulsoriamente, é a impressão rápida que prevalece, em detrimento da análise paulatina e sistemática. Essa questão acaba configurando-se como mais um agravante na análise do problema aqui examinado.

A importância dos gráficos estatísticos como ferramentas que traduzem e resumem grandes grupos de dados é inegável. São poderosos instrumentos de comunicação, capazes de modelar e explicar fenômenos, convencer a opinião pública e, muitas das vezes, interferir mesmo em decisões importantes, tais como o planejamento de uma empresa ou a escolha do voto. Como toda ferramenta estatística, seu consumo está condicionado à manutenção de conhecimentos específicos de base matemática e interpretativa. Espera-se de um adulto estatisticamente letrado que seja capaz de identificar todos (ou a maioria) dos problemas abordados nos gráficos analisados neste trabalho. Também espera-se que seja capaz de fazer aquilo que Curcio (1987) chama de ler entre os dados e ler além dos dados, significando a capacidade de identificar tendências e padrões gerais no gráfico (ao invés de

\footnotetext{
${ }^{3}$ Estamos nos referindo à área da Educação Estatística.
} 
focar em certas áreas isoladamente), e o entendimento de que projeções podem ser feitas com os dados (extrapolação).

De um modo geral, a elaboração e consumo adequados de gráficos e outras ferramentas estatísticas são fatores intrínsecos a qualquer sociedade estatisticamente letrada. Se, de um lado, não é papel do leitor tomar as informações de forma acrítica; de outro, é obrigação do autor fornecer ao leitor todos os elementos necessários à leitura adequada do gráfico, imprimindo-Ihe tanto os princípios técnico-normativos de elaboração, quanto os princípios éticos de conduta e compromisso com a informação.

\section{Referências}

BESSON, J. L. A ilusão das Estatísticas. São Paulo: Unesp, 1992. 289 p.

BORGES, R. As pesquisas não devem acertar quem será o prefeito da sua cidade. El país, São Paulo, 24 ago. 2016. Disponível em:

<https://brasil.elpais.com/brasil/2016/02/16/politica/ 1455635084_281459.html>. Acesso em: 21 jul. 2018.

CARNEIRO, J. Edifício Aqua, 31 andares: construtora tem quase 340 ações na justiça do trabalho. Blog do Jeso, 09 abr. 2017. Disponível em: < http://www.jesocarneiro.com.br/ negocios/aqua-31-andares-construtora-tem-quase-340-acoes-na-justica-dotrabalho.html>. Acesso em: 03 mai. 2018.

CAZORLA, I. M.; CASTRO, F. C. O Papel da Estatística na Leitura do Mundo: O Letramento Estatístico. Publicatio UEPG Ciências humanas, linguística, letras e artes, v. 16, n. 1, p. 45-53. 2008.

CURCIO, F. R. Comprehension of mathematical relationships expressed in graphs. Journal for Research in Mathematics Education, v. 18, p. 382-393. 1987.

CURY, A. Na bolsa, crise grega 'apaga' bom momento da economia brasileira. Portal G1, São Paulo, 17 jun. 2011. Disponível em: <

http://g1.globo.com/economia/mercados/noticia/2011/ 06/na-bolsa-crise-grega-apagabom-momento-da-economia-brasileira.html>. Acesso em: 24 jun. 2018.

CRESPO, A. A. Estatística Fácil. São Paulo: Saraiva, 2002. 224 p.

EXAME: Revista semanal. São Paulo: ed. Abril, n. 1139, 7 jun. 2017.

FIORENTINI, D.; LORENZATO, S. Investigação em Educação matemática: percursos teóricos e metodológicos. 3․ Ed. São Paulo: Autores Associados, 2009. 228p.

GAL, I. Adults' statistical literacy: meanings, components, responsibilities. International statistical review, v. 70, n. 1, p. 1-25. 2002.

HUFF, D. Como mentir com estatística. Rio de Janeiro: Intrínseca, 2016. 130 p.

MORENO, A. C. Um quarto das escolas públicas não aborda o racismo em atividades extras na sala de aula. Portal G1, São Paulo, 21 mar. 2018. Disponível em:

<https://g1.globo.com/educacao/noticia/um-quarto-das-escolas-publicas-nao-aborda-oracismo-em-atividades-extras-na-sala-de-aula.ghtml>. Acesso em: jun. 2018. 
PORTAL IG. 2010 fecha com um milhão de matrículas a menos em educação básica. Portal IG, São Paulo, 20 dez. 2010. Disponível em: < https://ultimosegundo.ig.com.br/educacao/2010-fecha-com-um-milhao-de-matriculas-amenos-em-educacao-basica/n1237887331491.html > . Acesso em: 15 jun. 2018.

PORTAL R7. Homem branco ganha quase R $\$ 1500$ a mais por mês do que mulher negra no Brasil. Portal R7, São Paulo, 06 mar. 2017. Disponível em: <https://noticias.r7.com/brasil/ homem-branco-ganha-quase-r-1500-a-mais-por-mes-do-que-mulher-negra-no-brasil06032017>. Acesso em: 19 mai. 2018.

SOUZA, G. A. A manipulação dos dados estatísticos pela mídia impressa. In: CONGRESSO BRASILEIRO DE CIÊNCIAS DA COMUNICAÇÃO, .32, 2009. Anais... Curitiba, 2009. p. 1-15.

TOLEDO, G. L.; OVALLE, I. I. Estatística Básica. São Paulo: Atlas, 1981. 